
Not for reproduction, distribution or commercial use.

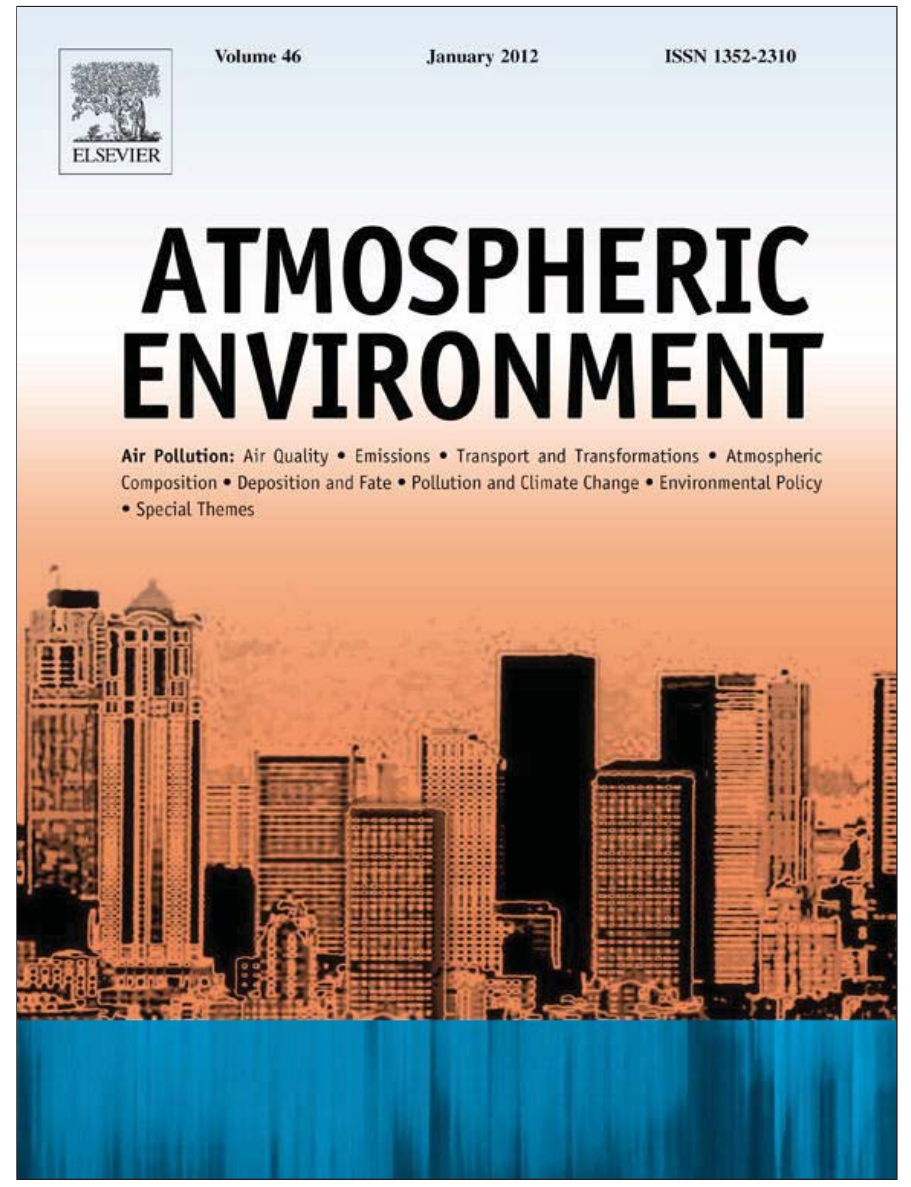

This article appeared in a journal published by Elsevier. The attached copy is furnished to the author for internal non-commercial research and education use, including for instruction at the authors institution and sharing with colleagues.

Other uses, including reproduction and distribution, or selling or licensing copies, or posting to personal, institutional or third party websites are prohibited.

In most cases authors are permitted to post their version of the article (e.g. in Word or Tex form) to their personal website or institutional repository. Authors requiring further information regarding Elsevier's archiving and manuscript policies are encouraged to visit: 


\title{
New Directions: Emerging satellite observations of above-cloud aerosols and direct radiative forcing ${ }^{\text {is }}$
}

\author{
A B S T R A C T
}

Keywords:

Aerosol above clouds

Radiative forcing

Satellite remote sensing
Spaceborne lidar and passive sensors with multi-wavelength, multi-angle and polarization capabilities onboard the A-Train provide unprecedented opportunities of observing above-cloud aerosols and direct radiative forcing. Significant progress has been made in recent years in exploring these new aerosol remote sensing capabilities and generating unique datasets. The emerging observations will advance the understanding of aerosol climate forcing.

(c) 2013 Elsevier Ltd. All rights reserved.
Aerosols affect the Earth's energy budget directly by scattering and absorbing the solar radiation in both cloud-free and cloudy conditions, which is referred to the direct radiative forcing (DRF). Advances in passive aerosol remote sensing during the era of Earth Observing System have provided valuable constraints to the estimate of cloudfree DRF (Yu et al., 2006). On the other hand, estimate of cloudy-sky DRF is poorly constrained because conventional aerosol retrievals from passive sensors are performed only in cloud-free conditions. Large inter-model discrepancies exist in the cloudy-sky DRF, with global annual mean values for the top-of-atmosphere (TOA) DRF ranging from -0.16 (cooling) to $+0.34 \mathrm{~W} \mathrm{~m}^{-2}$ (warming) (Schulz et al., 2006). Unraveling these discrepancies require reliable, observational constraints of both aerosol and cloud properties.

The co-existence of aerosols and clouds in the same atmospheric column complicates the interactions of aerosol with sunlight, because clouds reflect a substantial amount of incident radiation back to space. Compared to that in cloud-free conditions, aerosols would generally intercept more (less) solar radiation if they reside above (beneath) clouds. In particular, when aerosols reside above clouds, aerosol absorption can be substantially amplified due to multiple scattering between aerosol and underlying cloud, leading to a less negative or even positive DRF at TOA. Estimating DRF by aerosols above clouds remains a big challenge because of the interplay of several aerosol and cloud properties, all subject to large uncertainties, including aerosol optical depth (AOD), aerosol singlescattering albedo, cloud fraction, and cloud optical depth (COD). Large-scale measurements of aerosol above clouds and DRF had been unexplored until recently when the A-Train formed. The ATrain is a constellation of several satellites carrying a suite of active and passive sensors with enhanced capabilities, including the Moderate resolution Imaging Spectroradiometer (MODIS) on Aqua, the Ozone Measurement Instrument (OMI) on Aura, the Polarization and Directionality of Earth Reflectances (POLDER) on PARASOL,

\footnotetext{
is Something to say? Comments on this article, or suggestions for other topics, are welcome. Please contact: new.directions@uea.ac.uk, or go to atmos_env@uea.ac.uk, http://www.elsevier.com/wps/find/journaldescription.cws_home/246/ authorinstructions for further details.
}

and the Cloud-Aerosol Lidar with Orthogonal Polarization (CALIOP) on CALIPSO. Aqua, CALIPSO, PARASOL, and Aura overpass the equator each day successively within a few minutes around 1:30 p.m. local time, making it feasible to integrate multi-sensor observations for aerosol and cloud research. The A-Train offers unprecedented opportunities of observing aerosols above clouds and their direct radiative forcing, owing to the utilization of lidar, multiwavelength, multi-angle, and polarization techniques.

CALIOP is the first satellite lidar to provide multi-year continuous measurements of aerosol and cloud profiles on a global scale (Winker et al., 2010). Looking down from space the CALIOP active beam can penetrate through high-level, optically thin clouds and detect the aerosol and cloud layers in middle troposphere and in the boundary layer. Thus CALIOP is unique in providing retrieved profiles of aerosol backscattering and extinction in clear sky and above low-level clouds. Fig. 1 shows seasonal mean above-cloud AOD (ACAOD) in 2007 derived from CALIOP 5-km aerosol and cloud layer products. Clearly shown in this climatology map are hot spots of ACAOD associated with strong sources of biomass burning smoke, desert dust, or industrial pollution. In addition to the conventional lidar AOD retrieval algorithm based on lidar ratio and backscatter observations, research algorithms have also been developed to retrieve above-cloud AOD and particle properties based on the contrast of CALIOP observations of depolarization ratio (Hu et al., 2007) and color ratio (Chand et al., 2008) between clean clouds and clouds contaminated by above-cloud aerosols. Chand et al. (2009) used CALIOP observations of above-cloud AOD and MODIS observations of cloud fraction and cloud optical depth, both aggregated to monthly averages over $5^{\circ} \times 5^{\circ}$ boxes, to calculate the direct radiative effect of smoke located above low-level clouds in the southeastern Atlantic off the coast of southern Africa. Such aggregations are required because of CALIOP's narrow swath. Assumptions implicitly made in this approach include: (1) above-cloud aerosols detected by CALIOP along its track are representative of the $5^{\circ} \times 5^{\circ}$ box; (2) the day-to-day co-variation of cloud properties (cloud fraction and optical depth) with ACAOD is negligible; (3) the above-cloud aerosols have negligible impact on the MODIS cloud retrievals. These assumptions are not well 
(a) $2007 \mathrm{DJF}$

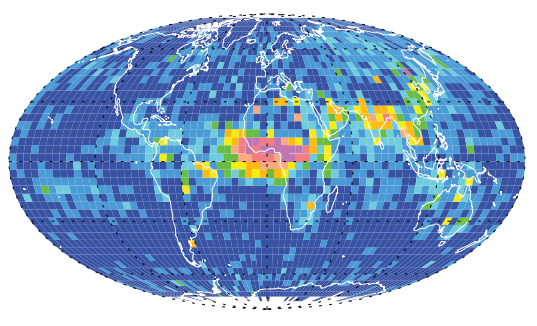

(c) 2007 JJA

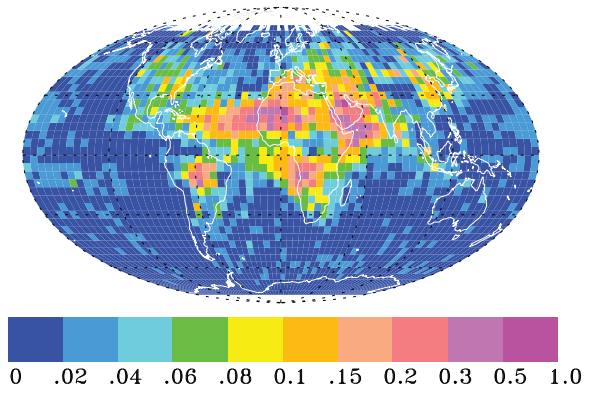

(b) 2007 MAM

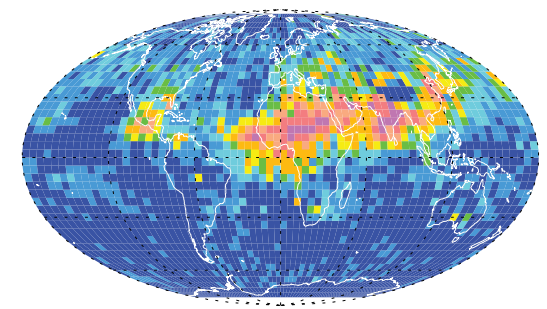

(d) $2007 \mathrm{SON}$
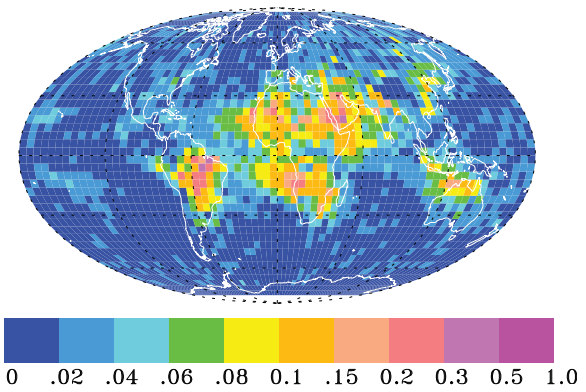

Fig. 1. CALIOP seasonal mean AOD (at $532 \mathrm{~nm}$ ) above low-level clouds (cloud top less than $4 \mathrm{~km}$ ) for 2007. CALIOP 5 -km aerosol and cloud layer products are aggregated into $5^{\circ} \times 4^{\circ}$ grids during a season. AOD is set to 0 when CALIOP doesn't detect aerosol layers above clouds.

justified, which constitutes unknown sources of error in the forcing estimate.

Measurements from passive sensors also include information content of above-cloud aerosols, although conventional aerosol retrievals have been limited to cloud-free column. Interactions of above-cloud aerosols with solar radiation reflected by underlying clouds and surface can bring about changes in some attributes (spectral variation, and polarization) of radiance that can be well discerned by several current-generation sensors. Because smoke, pollution, dust aerosols have larger absorption AOD at shorter wavelengths than longer wavelengths (Russell et al., 2010), their perturbations to reflectance by underlying clouds vary with wavelengths. Aerosols can also significantly affect the polarized light reflected by underlying clouds in certain ranges of scattering angles. Fig. 2 shows distinctive signatures induced by smoke above-clouds that are observed by MODIS/Aqua, OMI, and POLDER. CALIOP profiling (Fig. 2a) indicates a smoke layer between 2 and $4 \mathrm{~km}$ overlying a cloud deck top at $0.7-1.3 \mathrm{~km}$, which extends from $17^{\circ} \mathrm{S}$ to $6^{\circ} \mathrm{S}$ over Atlantic Ocean. In contrast, south of $21^{\circ} \mathrm{S}$ the air above low-level clouds is relatively clean. MODIS true color image overlaid with the CALIOP track and marked representative smoky region (box S) and clean region (box $\mathrm{C}$ ) provide a large-scale perspective of aerosol and cloud settings. The smoke above clouds yields a pronounced spectral signature as shown in MODIS reflectance color ratio between $470 \mathrm{~nm}$ and $1240 \mathrm{~nm}$ (Fig. 2c). In unpolluted clean region $\mathrm{C}$, the color ratio is greater than 1.0 because of the stronger molecular scattering at $470 \mathrm{~nm}$. In the smoky regions (e.g., S) the color ratio is substantially smaller, because the attenuation of cloud reflectance by smoke absorption is much stronger at $470 \mathrm{~nm}$ than $1240 \mathrm{~nm}$. The impact of smoke on cloud reflectance is also discernable from OMI observations of absorbing aerosol index (AI) in the UV range, a quantity that reflects spectral variations of the interaction between aerosol absorption and Rayleigh scattering (Herman et al., 1997). While AI has near-zero value for Rayleigh scattering atmosphere, clouds, and non-absorbing aerosols, AI is positive for absorbing aerosols in both clear scenes and above clouds. In this case, AI is 2-3 in the smoky region S, much larger than $\sim 0.5$ in unpolluted clean region C. Fig. 2e shows the polarized reflectance at $865 \mathrm{~nm}$ observed by POLDER as a function of scattering angle in $\mathrm{C}$ (blue dots) and $\mathrm{S}$ (red dots) regions. In unpolluted cloudy scene $(\mathrm{C})$, there is a strong peak of polarization around $140^{\circ}$ corresponding to the primary cloud-bow and very small levels of polarization at side scattering angles of $80^{\circ}-130^{\circ}$. Note that when COD $>3$, the polarized reflectance by cloud is independent of cloud albedo or "saturated". In smoke-over-cloud scene (S), the polarized reflectance is attenuated in the primary cloud-bow but enhanced significantly at the side scattering angles. Although non-spherical mineral dust will not significantly enhance the polarization at the side scattering angles, it can attenuate the polarized reflectance in the primary bow (Waquet et al., 2012). The example discussed above clearly demonstrates that aerosols above clouds can be discriminated from the spectral and angular characteristics of reflectance and polarized light by the advanced passive sensors onboard the A-Train. As recently shown in the published literature (Waquet et al., 2009; Torres et al., 2012; Yu et al., 2012a; Jethva et al., in press), these passive sensors provide alternatives for retrieving above-cloud aerosols that can overcome the limitation of CALIOP nadir observations over narrow swath.

Estimating ACAOD and some aerosol properties from the signatures observed by the passive sensors has been explored very recently. Waquet et al. (2009) used the changes of angular distributions of the polarized light at a single wavelength to retrieve ACAOD for a smoke case from POLDER multi-angle polarization measurements. The algorithm has been further extended to the retrievals of ACAOD of both smoke and mineral dust and the particle size parameter using POLDER measurements of the polarized reflectances at three wavelengths and at both the primary cloud-bow and a range of side scattering angles (Waquet et al., 2012). Knobelspiesse et al. (2011) showed a capability of simultaneously retrieving ACAOD and cloud optical properties from multi-angle, multi-spectral, passive observations of polarized reflectance from an aircraft prototype of scanning polarimeter designed for the Glory satellite (unfortunately it was not successfully launched). The spectral signatures in the reflected radiation have been 
a) CALIOP Attenuated Backscatter
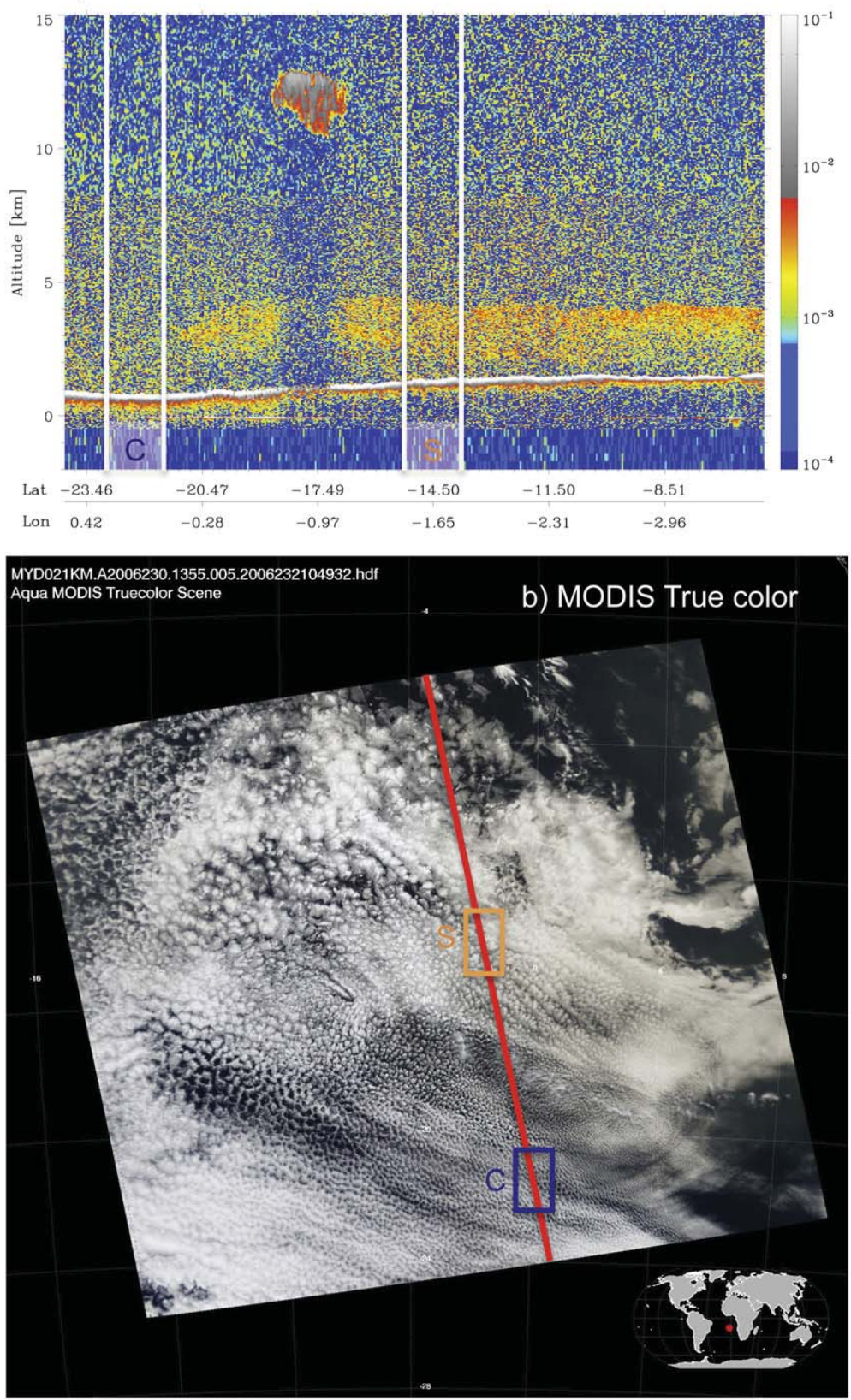
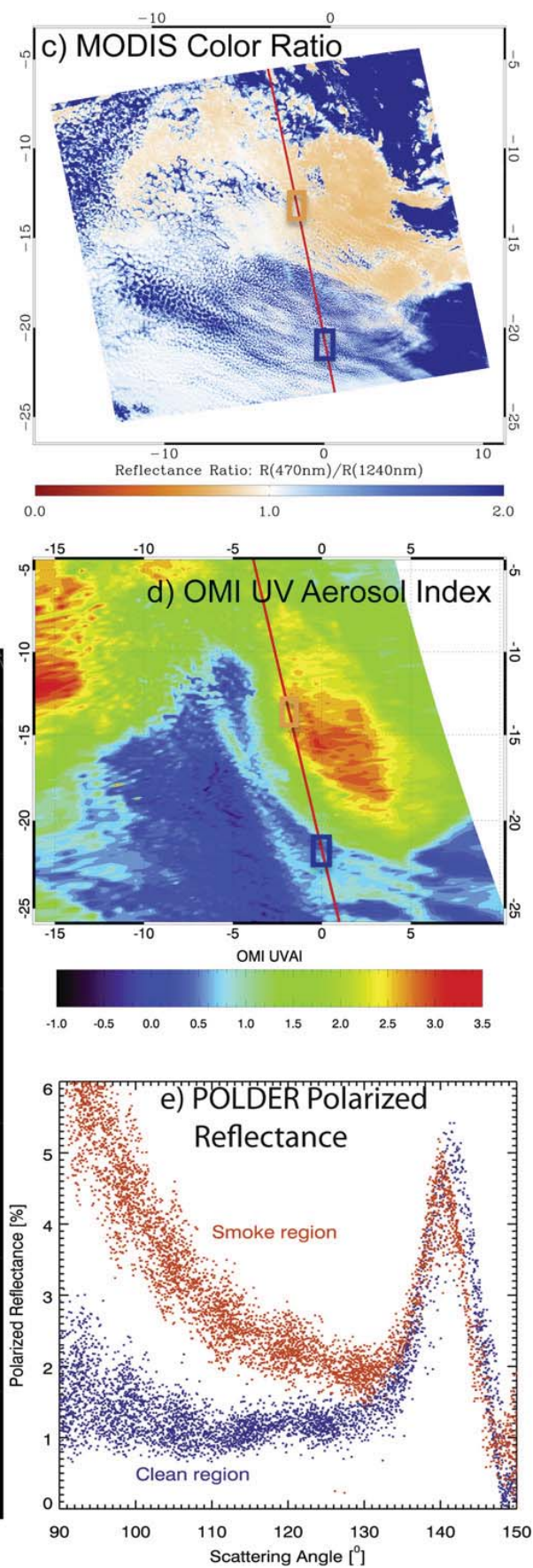

Fig. 2. A-Train observations of smoke aerosol above clouds over Atlantic Ocean off the coast of southwestern Africa on August 18, 2006: (a) CALIOP attenuated backscatter $\left(\mathrm{km}^{-1} \mathrm{sr}^{-1}\right)$ profile, showing extensive aerosol layer above clouds north of $17^{\circ} \mathrm{S}$ and relatively clean air south of $21^{\circ} \mathrm{S}$ (a representative smoky region - box $\mathrm{S}$ and clean region box C are marked for reference); (b) MODIS true color image with the CALIOP track overlaid; (c) MODIS color ratio for the reflectance at 470 and 1240 nm; (d) OMI UV aerosol index; and (e) POLDER polarized reflectance at 865 as a function of scattering angle in the clean (blue dots) and smoky (red dots) regions.

explored to simultaneously retrieve ACAOD and COD of underlying cloud from multi-wavelength sensors like OMI (Torres et al., 2012) and MODIS (Jethva et al., in press) on a basis of case studies. For these algorithms, ACAOD is retrieved with other aerosol properties generally assumed as a priori. While some algorithms show a potential of retrieving some aerosol microphysical properties (Knobelspiesse et al., 2011; Waquet et al., 2012), their uncertainties are likely larger than that for ACAOD. These studies demonstrate that it is promising to retrieve ACAOD with extensive spatial coverage from passive sensors with multi-wavelength and multiangle polarization capabilities.

Integrating complementary observables from the A-Train sensors could provide an empirical approach to estimating ACAOD with extensive coverage. AI is a semi-quantitative measure of ACAOD because it depends on aerosol height, single-scattering albedo, and cloud albedo. The multiple scattering between aerosol 
layer and underlying cloud deck enhances AI, but reduces the AI dependence on the height of aerosol layer (Torres et al., 2012; de Graaf et al., 2005). Yu et al. (2012a) found that for collocated CALIOP and OMI measurements, OMI AI correlates well with CALIOP ACAOD when the analysis is stratified with collocated MODIS COD in the outflow regions of South Africa smoke and North Africa dust. Such derived ACAOD-AI relationships could constitute a basis for potentially developing an empirical approach to deriving daily above-cloud AOD from OMI semi-quantitative AI and MODIS cloud measurements with much more extensive spatial coverage over longer duration than do CALIOP observations. Significant efforts are needed to further explore this approach, including the characterization of the viewing-geometry dependence of ACAOD-AI relationship, and quantification of CALIOP AOD bias and uncertainties.

The observations of ACAOD can be used to calculate DRF by above-cloud aerosols, with aerosol optical properties such as single-scattering albedo and asymmetry factor being constrained by in-situ or remote sensing measurements and cloud optical depth from satellites. Cautions should be exercised when using satellite measurements of cloud optical depth, because above-cloud aerosols can contaminate the cloud optical depth retrievals from passive sensors, such as MODIS, leading to a biased DRF estimation. For example, a layer of absorbing aerosols above cloud acts to reduce the cloud reflectance in visible and near IR, which leads to low bias in COD retrieval (Haywood et al., 2004; Wilcox et al., 2009; Coddington et al., 2010; Torres et al., 2012). If not corrected, this COD bias will in turn propagate to the DRF computation. The problem could be alleviated through using a spectral band that is less affected by above-cloud aerosols for COD retrieval. In the smoke over cloud scenario, for example, smoke AOD decreases with wavelength quickly while COD remains almost constant over the solar spectrum. As a result, the above-cloud smoke has limited impact on cloud reflectance in shortwave infrared (SWIR) or longer wavelengths, although the impact in visible or near infrared could be significant. Recently, Meyer et al. (submitted for publication) used collocated CALIPSO ACAOD retrieval to estimate and correct the MODIS COD retrieval bias. They found that the DRF of ACAOD computed based on the corrected COD retrieval can be up to roughly $10 \%$ larger than that based on the uncorrected COD retrieval. The COD retrieval bias caused by ACAOD could be alleviated through using a spectral band that is less affected by above-cloud aerosols for COD retrieval. In the smoke over cloud scenario, for example, smoke AOD decreases with wavelength quickly while COD remains almost constant over the solar spectrum. As a result, the above-cloud smoke has limited impact on cloud reflectance in shortwave infrared (SWIR) or longer wavelengths, although the impact in visible or near infrared could be significant (de Graaf et al., 2012). Applying this approach to above-cloud dust conditions can be further complicated by significant impact of dust scattering in SWIR band, although impact of dust absorption is much smaller in SWIR than $865 \mathrm{~nm}$ band. Most recently, algorithms are being developed for simultaneous retrieval of both ACAOD and COD using MODIS spectral observations (Jethva et al., in press). A major advantage of these new algorithms is that the impact of above-cloud aerosol is taken into account in the COD retrieval. On the other hand, developing such algorithms involving both aerosol and cloud retrievals may be challenging, which requires more efforts to explore the algorithms and evaluate/validate the retrievals.

The above-cloud aerosol direct radiative forcing at TOA has also been estimated from satellite measurements of radiances/fluxes, which bypasses assumptions of aerosol optical properties and cloud optical depth required by the forward calculation discussed above. Hsu et al. (2003) derived regional TOA DRF induced by smoke aerosols of Southeast Asia by contrasting satellite measurements of radiative fluxes between clean and smoke contaminated pixels identified with AI. Peters et al. (2011) performed multiple linear regressions of satellite measurements to derive statistical relationships between planetary albedo, cloud liquid water path, and clear-sky AOD in the presence of low-level liquid water clouds based on three-year data over tropical and sub-tropical Atlantic Ocean. They found a decrease of the planetary albedo with increasing clear-sky AOD for mostly absorbing aerosols. However, the assumption that MODIS clear-sky AOD is representative of ACAOD was not justified, which could have introduced large uncertainties to the estimated DRF. Most recently, de Graaf et al. (2012) retrieved the cloud parameters from a pair of SWIR channels (i.e., 1246/ $1640 \mathrm{~nm}$ ) where smoke has relatively small AOD and its effects on cloud retrievals can be neglected. Using the retrieved cloud parameters together with satellite geometrical parameters, and prescribed surface albedo and ozone profiles, the cloudy-scene TOA reflectance without aerosol is calculated with a radiative transfer model. A difference between space-based spectrometer measurements of reflectance with the model calculated cloudy-scene TOA reflectance indicates the radiative impacts of smoke above clouds. The advantage of this approach is that it bypasses the assumption of aerosol microphysical properties and retrieval of ACAOD. On the other hand, the approach would be subject to large uncertainties when smoke is so intense that aerosol interference in SWIR cloud retrieval is not negligible. The approach would not be applied to dust because of spectrally flat AOD of dust. All these methods only provide estimates of TOA DRF, which is not adequate for fully understanding aerosol impacts on climate. For example, atmospheric heating rate induced by above-cloud aerosols is essential to the understanding of aerosol impacts on the development of underlying clouds (Wilcox, 2010).

In closing, recent developments in both active and passive remote sensing provide an unprecedented opportunity for quantifying aerosols above clouds and advancing the understanding of aerosol climate forcing. Future efforts are needed to further explore these capabilities and improve the accuracy of ACAOD and DRF. Although the lack of reliable measurements makes it challenging to conduct rigorous validations of satellite retrievals of ACAOD and DRF, inter-comparing different methods should be carefully performed, keeping in mind the strengths and limitations of individual methods. In addition to providing observational constraints for aerosol DRF and impacts on cloud development, satellite observations of ACAOD can be used to improve the estimate of aerosol intercontinental transport (Yu et al., 2008, 2012b), because the cross-ocean transport often occurs above the low-level clouds.

\section{Acknowledgments}

HY acknowledge the NASA support via NNX11AH66G and NNX11AJ91G, both administered by R. Eckman. ZZ acknowledges the Startup fund from the University of Maryland, Baltimore County. We thank Hyoun-Myoung Cho for helping in producing the image and Yuekui Yang and Dan Miller for helpful discussion. The authors are grateful to NASA for providing A-Train satellite data used in this study, including MODIS, CALIPSO and OMI products. The authors are grateful to CNES for providing POLDER/ PARASOL data. ZZ thanks the ICARE Data and Services Center for providing access to the data and for general assistance and development support.

\section{References}

Chand, D., Anderson, T., Wood, R., Charlson, R.J., Hu, Y., Liu, Z., Vaughan, M., 2008. Quantifying above-cloud aerosol using spaceborne lidar for improved understanding of cloudy-sky direct climate forcing. J. Geophys. Res. 113. http:// dx.doi.org/10.1029/2007JD009433. D13206. 
Chand, D., Wood, R., Anderson, T.L., Satheesh, S.K., Charlson, R.J., 2009. Satellitederived direct radiative effect of aerosols dependent on cloud cover. Nat. Geosci. 2, 181-184. http://dx.doi.org/10.1038/ngeo437.

Coddington, O.M., Pilewskie, P., Redemann, J., Platnick, S., Russell, P.B., Schmidt, K.S Gore, W.J., Livingston, J., Wind, G., Vukicevic, T., 2010. Examining the impact of overlying aerosols on the retrieval of cloud optical properties from passive remote sensing. J. Geophys. Res. 115. http://dx.doi.org/10.1029/2009JD012829. D10211.

de Graaf, M., Stamnes, P., Torres, O., Koelemeijer, R.B.A., 2005. Absorbing aerosol index: sensitivity analysis, application to GOME and comparison with TOMS. J. Geophys. Res. 110, D01201. http://dx.doi.org/10.1029/2004JD005178.

de Graaf, M., Tilstra, L.G., Wang, P., Stammes, P., 2012. Retrieval of the aerosol direct radiative effect over clouds from spaceborne spectrometry. J. Geophys. Res. 117. http://dx.doi.org/10.1029/2011JD017160. D07207.

Haywood, J.M., Osborne, S.R., Abel, S.J., 2004. The effect of overlying absorbing aerosol layers on remote sensing retrievals of cloud effective radius and cloud optical depth. Q. J. R. Meteorol. Soc. 130, 779-800.

Herman, J., Bhartia, P., Torres, O., Hsu, C., Seftor, C., Celarier, E., 1997. Global distribution of UV-absorbing aerosols from Nimbus-7/TOMS data. J. Geophys. Res. 102 16911-16922.

Hsu, N.C., Herman, J.R., Tsay, S.-C., 2003. Radiative impacts from biomass burning in the presence of clouds during boreal spring in southeast Asia. Geophys. Res. Lett. 30, 1224. http://dx.doi.org/10.1029/2002GL016485.

Hu, Y., Vaughan, M.A., Liu, Z., Powell, K., Rodier, S., 2007. Retrieving optical depths and lidar ratios for transparent layers above opaque water clouds from CALIPSO lidar measurements. IEEE Geosci. Remote Sens. Lett. 4, 523-526.

Jethva, H., Torres, O., Remer, L.A., Bhartia, P.K. A color ratio method for simultaneous retrieval of aerosol and cloud optical thickness of above cloud absorbing aerosols from passive sensors: applications to MODIS measurements. IEEE Trans. Geosci. Remote Sens., in press.

Knobelspiesse, K., Cairns, B., Redemann, J., Bergstrom, R.W., Stohl, A., 2011. Simultaneous retrieval of aerosol and cloud properties during the MILAGRO field campaign. Atmos. Chem. Phys. 11, 6245-6263. http://dx.doi.org/10.5194/acp11-6245-2011.

Meyer, K., Platnick, S.E., Oraiopoulos, L., Lee, D.M. Estimating the direct radiative effect of absorbing aerosols overlying marine boundary layer clouds in the southeast Atlantic using MODIS and CALIOP. J. Geophys. Res., submitted for publication.

Peters, K., Quaas, J., Bellouin, N., 2011. Effects of absorbing aerosols in cloudy skies: a satellite study over the Atlantic Ocean. Atmos. Chem. Phys. 11, 1393-1404. http://dx.doi.org/10.5194/acp-11-1393-2011.

Russell, P.B., Bergstrom, R.W., Shinozuka, Y., Clarke, A.D., DeCarlo, P.F., Jimenez, J.L., Livingston, J.M., Redemann, J., Dubovik, O., Strawa, A., 2010. Absorption angstrom exponent in AERONET and related data as an indicator of aerosol composition. Atmos. Chem. Phys. 10, 1155-1169. http://dx.doi.org/10.5194/acp-10-1155-2010.

Schulz, M., et al., 2006. Radiative forcing by aerosols as derived from the AeroCom present-day and pre-industrial simulations. Atmos. Chem. Phys. 6, 5225-5246.

Torres, O., Jethva, H., Bhartia, P.K., 2012. Retrieval of aerosol optical depth over clouds from OMI observations: sensitivity analysis and case studies. J. Atmos. Sci. 69, 1037-1053. http://dx.doi.org/10.1175/JAS-D-11-0130.1.

Waquet, F., Riedi, J., Labonnote, C., Goloub, P., Cairns, B., Deuze, J.-L., Tanre, D., 2009 Aerosol remote sensing over clouds using A-Train observations. J. Atmos. Sci, 66 2468-2480.
Waquet, F., Cornet, C., Deuze, J.-L., Dubovik, O., Ducos, F., Goloub, P., Herman, M., Lapionak, T., Labonnote, L., Riedi, J., Tanre, D., Thieuleux, F., Vanbauce, C., 2012. Retrieval of aerosol microphysical and optical properties above liquid clouds from POLDER/PARASOL polarization measurements. Atmos. Meas. Tech. Discuss. 5, 6083-6145.

Wilcox, E.M., Harshvardhan, Platnick, S., 2009. Estimate of the impact of absorbing aerosol over cloud on the MODIS retrievals of cloud optical thickness and effective radius using two independent retrievals of liquid water path. J. Geophys. Res. 114, D05210. http://dx.doi.org/10.1029/2008JD010589.

Wilcox, E.M., 2010. Stratocumulus cloud thickening beneath layers of absorbing smoke aerosol. Atmos. Chem. Phys. 10, 11769-11777.

Winker, D.M., et al., 2010. The CALIPSO mission: a global 3D view of aerosols and clouds. Bull. Am. Met. Soc. 91, 1211-1229.

Yu, H., Kaufman, Y.J., Chin, M., Feingold, G., Remer, L., Anderson, T., Balkanski, Y., Bellouin, N., Boucher, O., Christopher, S., DeCola, P., Kahn, R., Koch, D., Loeb, N., Reddy, M.S., Schulz, M., Takemura, T., Zhou, M., 2006. A review of measurement-based assessments of aerosol direct radiative effect and forcing. Atmos. Chem. Phys. 6, 613-666.

Yu, H., Remer, L.A., Chin, M., Bian, H., Kleidman, R.G., Diehl, T., 2008. A satellitebased assessment of transpacific transport of pollution aerosol. J. Geophys. Res. 113, D14S12. http://dx.doi.org/10.1029/2007JD009349.

Yu, H., Zhang, Y., Chin, M., Liu, Z., Omar, A., Remer, L.A., Yang, Y., Yuan, T., Zhang, J., 2012a. An integrated analysis of aerosol above clouds from A-Train multi-sensor measurements. Remote Sens. Environ. 121, 125-131.

Yu, H., Remer, L.A., Chin, M., Bian, H., Tan, Q., Yuan, T., Zhang, Y., 2012b. Aerosols from overseas rival domestic emissions over North America. Science 337, 566-569.

Hongbin $\mathrm{Yu}^{*}$

Earth System Science Interdisciplinary Center, University of Maryland, College Park, MD 20740, USA

Earth Science Directorate, NASA Goddard Space Flight Center, Greenbelt, MD 20771, USA

Zhibo Zhang ${ }^{1}$

Department of Physics, University of Maryland at Baltimore County, Baltimore, MD 21228, USA

Joint Center for Earth Systems Technology, University of Maryland at Baltimore County, Baltimore, MD 21228, USA E-mail address: Zhibo.Zhang@umbc.edu

* Corresponding author. Earth Science Directorate, NASA Goddard Space Flight Center, Greenbelt, MD 20771, USA. Tel.: +1 301614 6209; fax: +1 3016146307 . E-mail addresses: Hongbin.Yu@gmail.com, Hongbin.Yu@nasa.gov (H. Yu) 


\title{
New Direction
}

\section{Emerging Satellite Observations of Above-Cloud Aerosols and Direct Radiative Forcing}

\author{
Hongbin $\mathrm{Yu}^{1,2}$ and Zhibo Zhang ${ }^{3,4}$ \\ ' Earth System Science Interdisciplinary Center, University of Maryland, College Park, \\ Maryland, 20740, USA \\ ${ }^{2}$ Earth Science Directorate, NASA Goddard Space Flight Center, Greenbelt, Maryland, \\ 2077I, USA \\ ${ }^{3}$ Department of Physics, University of Maryland at Baltimore County, Baltimore, \\ Maryland, 21228 , USA \\ ${ }^{4}$ Joint Center for Earth Systems Technology, University of Maryland at Baltimore \\ County, Baltimore, Maryland, 2 I228, USA
}

Keywords: Aerosol above clouds, Radiative forcing, Satellite remote sensing

Abstract: Spaceborne lidar and passive sensors with multi-wavelength and polarization capabilities onboard the A-Train provide unprecedented opportunities of observing above-cloud aerosols and direct radiative forcing. Significant progress has been made in recent years in exploring these new aerosol remote sensing capabilities and generating unique datasets. The emerging observations will advance the understanding of aerosol climate forcing.

Aerosols affect the Earth's energy budget directly by scattering and absorbing the solar radiation in both cloud-free and cloudy conditions, which is referred to the direct radiative forcing. Advances in aerosol passive remote sensing during the era of Earth Observing System have provided valuable constraints to the estimate of cloud-free DRF (Yu et al., 2006; Forster et al., 2007). On the other hand, estimate of cloudy-sky DRF is poorly constrained, because conventional aerosol retrievals from passive sensors are performed only in cloud-free conditions. A multi-model assessment showed that large inter-model differences exist in the cloudy-sky DRF, with global annual mean values for the top-of-atmosphere (TOA) DRF ranging from -0.16 to $+0.34 \mathrm{Wm}^{-2}$ (Schulz et al., 2006). In southeastern Atlantic Ocean off the coast of southern Africa particularly, the modeled values of TOA cloudy-sky DRF differ in magnitude and sign, varying from slightly negative to greater than $+5 \mathrm{Wm}^{-2}$ on an annual mean basis (Schulz et al., 2006). Unraveling these inter-model differences require reliable, observational constraints of both aerosol and cloud properties

The co-existence of aerosols and clouds in the same atmospheric column complicates the interactions of aerosol with sunlight, because clouds reflect a substantial amount of incident radiation back to space. Compared to that in cloud-free conditions, aerosols would generally absorb more (less) solar radiation if they reside above (beneath) clouds. In particular, when aerosols reside above clouds, aerosol absorption can be substantially 
amplified due to multiple scattering between aerosol layer and underlying cloud, leading to a less negative or even positive DRF (warming) at TOA (Keil and Haywood, 2003; Abel et al., 2005). Estimating DRF by aerosols above clouds remains a big challenge because of the interplay of several aerosol and cloud properties, such as aerosol optical depth (AOD), aerosol single-scattering albedo, cloud fraction, and cloud optical depth (COD), all subject to large uncertainties. Large-scale measurements of aerosol above clouds and DRF had been unexplored until recently when the A-Train formed (Stephens et al., 2002). The A-Train is a constellation of several satellites carrying a suite of active and passive sensors with enhanced capabilities, including the Moderate resolution Imaging Spectroradiometer (MODIS) onboard Aqua, the Ozone Measurement Instrument (OMI) onboard Aura, the Polarization and Directionality of Earth Reflectances (POLDER) onboard the Polarization and Anisotropy of Reflectances for Atmospheric Sciences Coupled with Observations from a Lidar (PARASOL), and the Cloud-Aerosol Lidar with Orthogonal Polarization (CALIOP) onboard the Cloud-Aerosol Lidar and Infrared Pathfinder Satellite Observation (CALIPSO). These satellites overpass the equator each day successively within a few minutes around I:30 p.m. local time, allowing for integrated studies of multi-sensor observations. The A-Train offers unprecedented opportunities of observing aerosols above clouds and their direct radiative forcing, owing to the utilization of lidar, multi-wavelength, multi-angle, and polarization techniques.

CALIOP is the first satellite lidar to provide multi-year continuous measurements of aerosol and cloud profiles on a global scale (Winker et al., 2009). Looking down from space the CALIOP laser light can penetrate through high-level, optically thin clouds and detect the aerosol and cloud layers in middle troposphere and in the boundary layer. Thus CALIOP is unique in providing retrieved profiles of aerosol backscattering and extinction in clear sky and above low-level clouds (Winker et al., 2010). Figure I shows seasonal mean above-cloud AOD (ACAOD) in 2007, which is derived from CALIOP 5 $\mathrm{km}$ aerosol and cloud layer products and aggregated to $5^{\circ} \times 4^{\circ}$ grids. Clearly shown in this climatology map are hot spots of ACAOD associated with strong sources of biomass burning smoke, desert dust, or industrial pollution. Research algorithms have also been developed to retrieve above-cloud AOD and particle properties based on the contrast of CALIOP observations of depolarization ratio (Hu et al., 2007) and color ratio (Chand et al., 2008) between clean clouds and contaminated clouds by above-cloud aerosols. Chand et al. (2009) used CALIOP observations of above-cloud AOD and MODIS observations of cloud fraction and cloud optical depth, both aggregated to monthly averages over $5^{\circ} \times 5^{\circ}$ boxes, to calculate the direct radiative effect of smoke located above low-level clouds in the southeastern Atlantic off the coast of southern Africa. Such the aggregations are required because of CALIOP's narrow swath. Assumptions implicitly made in this approach include: (I) above-cloud aerosols detected by CALIOP along its track are representative of the $5^{\circ} \times 5^{\circ}$ box; $(2)$ the day-to-day covariation of cloud properties (cloud fraction and optical depth) with ACAOD is negligible; (3) the above-cloud aerosols have negligible impact on the MODIS cloud retrievals. These assumptions are not well justified, which constitutes unknown sources of error in the forcing estimate. 
Measurements from passive sensors include information content of above-cloud aerosols, although conventional aerosol retrievals have been limited to cloud-free column. Interactions of above-cloud aerosols with solar radiation reflected by underlying clouds and surface can bring about changes in some attributes (spectral variation, and polarization) of radiance that can be well discerned by several current-generation sensors. Because smoke, pollution, dust aerosols have larger absorption AOD at shorter wavelengths than longer wavelengths (Russell et al., 2010), they perturb reflectance by underlying clouds differently in different wavelengths. Aerosols can also significantly affect the polarized light reflected by underlying clouds in certain scatteringangle ranges (Waquet et al., 2009, 2012). Figure 2 shows distinctive signatures induced by smoke above-clouds that are observed by MODIS/Aqua, OMI, and POLDER. CALIOP profiling (Figure $2 \mathrm{a}$ ) indicates a smoke layer between $2-4 \mathrm{~km}$ overlying a cloud deck top at 0.7 to $1.3 \mathrm{~km}$, which extends from $17^{\circ} \mathrm{S}$ to $6^{\circ} \mathrm{S}$ over Atlantic Ocean. On the contrary, south of $21^{\circ} \mathrm{S}$ the air above low-level clouds is relatively clean. MODIS true color image overlaid with the CALIOP track and marked representative smoky region (box S) and clean region (box $\mathrm{C}$ ) provide a large-scale perspective of aerosol and cloud settings. The smoke above clouds yields a pronounced spectral signature as shown in MODIS reflectance color ratio between $470 \mathrm{~nm}$ and $1240 \mathrm{~nm}$ (Figure 2c). In unpolluted clean region $\mathrm{C}$, the color ratio is greater than 1.0 because of the stronger molecular scattering at $470 \mathrm{~nm}$. In the smoky regions (e.g., S) the color ratio is substantially smaller, because the attenuation of cloud reflectance by smoke absorption is much stronger at $470 \mathrm{~nm}$ than $1240 \mathrm{~nm}$. The impact of smoke on cloud reflectance is also discernable from OMl observations of absorbing aerosol index (AI) in the UV range, a quantity that reflects spectral variations of the interaction between aerosol absorption and Rayleigh scattering (Herman et al., 1997). While Al has near-zero value for Rayleigh scattering atmosphere, clouds, and non-absorbing aerosols, $\mathrm{Al}$ is positive for absorbing aerosols in both clear scenes and above clouds. In this case, $\mathrm{Al}$ is 2-3 in the smoky region $\mathrm{S}$, much larger than $\sim 0.5$ in unpolluted clean region $C$. Figure 2(e) shows the polarized reflectance at $865 \mathrm{~nm}$ observed POLDER as a function of scattering angle in C (blue dots) and $S$ (red dots) regions. In unpolluted cloudy scene $(C)$, there is s strong peak of polarization around $140^{\circ}$ corresponding to the primary cloud-bow and very small levels of polarization at side scattering angles of $80^{\circ}$ to $130^{\circ}$. Note that when COD $>3$, the polarized reflectance by cloud is independent on cloud albedo or "saturated". In smokeover-cloud scene $(S)$, the polarized reflectance is attenuated in the primary cloud-bow but enhanced significantly at the side scattering angles. Note that although non-spherical mineral dust will not significantly enhance the polarization at the side scattering angles, it can attenuate the polarized reflectance in the primary bow (Waquet et al., 20I2). The example discussed above clearly demonstrates that aerosols above clouds can be discerned from the spectral and angular characteristics of reflectance and polarized light by the advanced passive sensors onboard the A-Train. These passive sensors provide potential alternatives for retrieving above-cloud aerosols that can overcome the limitation of CALIOP nadir observations over narrow swath.

Estimating ACAOD and some aerosol properties from the signatures observed by the passive sensors has been explored very recently. Waquet et al. (2009) used the changes of angular distributions of the polarized light at single wavelength to retrieve ACAOD 
for a smoke case from POLDER multi-angle polarization measurements. The algorithm has been further extended to the retrievals of ACAOD of both smoke and mineral dust and the particle size parameter using POLDER measurements of the polarized reflectances at three wavelengths and at both the primary cloud-bow and a range of side scattering angles (Waquet et al., 20I2). Knobelspiesse et al. (20II) showed a capability of simultaneously retrieving ACAOD and cloud optical properties from multi-angle, multispectral, passive observations of polarized reflectance from an aircraft prototype of scanning polarimeter designed for the Glory satellite (unfortunately it was not successfully launched). The spectral signatures in the reflected radiation have been explored to simultaneously retrieve ACAOD and COD of underlying cloud from multiwavelength sensors like OMI (Torres et al., 20I2) and MODIS (Jethva et al., 20/2) on a basis of case studies. For these algorithms, ACAOD is retrieved with other aerosol properties generally assumed as a priori. While some algorithms show a potential of retrieving some aerosol microphysical properties (Knobelspiesse et al., 20I I; Waquet et al., 20I2), uncertainties are larger than that for ACAOD. These studies, on a case basis in general, demonstrate that it is promising to retrieve ACAOD with extensive spatial coverage from passive sensors with multi-wavelength and polarization capabilities.

Integrating complementary observables from the A-Train sensors could provide an empirical approach to estimating ACAOD with extensive coverage. $\mathrm{Al}$ is a semiquantitative measure of $A O D$ because it also depends on aerosol height, singlescattering albedo, and cloud albedo. The multiple scattering between aerosol layer and underlying cloud deck enhances $\mathrm{Al}$, but reduces the $\mathrm{Al}$ dependence on the height of aerosol layer (Torres et al., 2012; de Graaf et al., 2005). Yu et al. (20I2a) found that for collocated CALIOP and OMI measurements, OMI Al correlates well with CALIOP ACAOD when the analysis is stratified with COD from MODIS, in the outflow regions of South Africa smoke and North Africa dust. Such derived ACAOD-AI relationships could constitute a basis for potentially developing an empirical approach to deriving daily above-cloud AOD from OMI semi-quantitative Al and MODIS cloud measurements with much more extensive spatial coverage over longer duration than do CALIOP observations. Significant efforts are needed to further explore this approach, including the characterization of the viewing-geometry dependence of ACAOD-Al relationship, and quantification of CALIOP AOD bias and uncertainties. One major advantage of such an empirical approach is that the derived ACAOD doesn't depend strongly on assumptions of aerosol microphysical properties.

The observations of ACAOD can be used to calculate DRF by above-cloud aerosols, with aerosol optical properties such as single-scattering albedo and asymmetry factor being constrained by in-situ or remote sensing measurements (e.g., Dubovik et al., 2002; Russell et al., 2010) and cloud optical depth from satellites. Cautions should be exercised when using satellite measurements of cloud optical depth, because above-cloud aerosols can potentially contaminate the cloud optical depth retrievals from passive sensors, such as MODIS, leading to a biased DRF estimation. For example, a layer of absorbing aerosols above cloud acts to reduce the cloud reflectance, which leads to low bias in COD retrieval (Haywood et al. 2004; Coddington et al., 2010). If not corrected, this COD bias will in turn propagate to the DRF computation. The problem could be alleviated through using a spectral band that is less affected by above-cloud aerosols for COD 
retrieval. In the smoke over cloud scenario, for example, smoke AOD decreases with wavelength quickly while COD remains almost constant over the solar spectrum. As a result, the above-cloud smoke has limited impact on cloud reflectance in shortwave infrared (SWIR) or longer wavelengths, although the impact in visible or near infrared could be significant. Recently, Meyer et al. (20/2) showed that the COD retrieval based on the $1.65 \mu \mathrm{m}$ MODIS band over southern Atlantic coast of Africa where smoke layer resides over marine stratocumulus deck is systematically lager than the operational retrieval based on the $0.86 \mu \mathrm{m}$ band. This difference is mainly attributed to the abovecloud smoke contamination in the $0.86 \mu \mathrm{m}$ band. It is also found that the DRF of smoke computed from the $1.65 \mu \mathrm{m}$ COD retrieval is stronger (more positive) than that based on the $0.86 \mu \mathrm{m}$ COD retrieval. On the other hand, using SWIR band for COD retrieval to alleviate above-cloud aerosol contamination is complicated by the fact that cloud droplet absorption becomes significant in this spectral region, which leads to saturation when cloud is thick (e.g., COD > 20). Applying this approach to above-cloud dust conditions can be further complicated by significant impact of dust scattering in SWIR band, although impact of dust absorption is much smaller in SWIR than $0.86 \mu \mathrm{m}$ band. Most recently, algorithms are being developed for simultaneous retrieval of both ACAOD and COD using MODIS spectral observations (Jethva et al. 2012; Meyer et al., 20/2). A major advantage of these new algorithms is that the impact of above-cloud aerosol is taken into account in the COD retrieval. On the other hand, developing such algorithms involving both aerosol and cloud retrievals may be challenging, which requires more efforts to explore the algorithms and evaluate/validate the retrievals.

The above-cloud aerosol direct radiative forcing at TOA has also been estimated from satellite measurements of radiances/fluxes, which avoids assumptions of aerosol optical properties and cloud optical depth required by the forward calculation discussed above. Hsu et al. (2003) derived regional TOA DRF induced by smoke aerosols of Southeast Asia by contrasting satellite measurements of radiative fluxes between clean and smoke contaminated pixels identified with Al from the Total Ozone Monitoring Spectrometer (TOMS). Similarly, Peters et al. (20ll) performed multiple linear regressions to derive statistical relationships between CERES planetary albedo, AMSR-E cloud liquid water path, and MODIS clear-sky AOD in the presence of low-level liquid water clouds as detected by MODIS based on three-year data over tropical and sub-tropical Atlantic Ocean. In the analysis, a threshold of OMI UV AI > 0.7 is used to identify the absorbingaerosol presence in cloudy scenes. They found a decrease of the planetary albedo with increasing clear-sky AOD for mostly absorbing aerosols. However, the assumption that MODIS cloud-free AOD is representative of above-cloud AOD has not been justified, which could introduce large uncertainties to the estimate of above-cloud aerosol DRF. Most recently, de Graaf et al. (20/2) retrieved the cloud parameters from a pair of SWIR channels (i.e., I246/1640 nm) where smoke has relatively small AOD and its effects on cloud retrievals can be neglected. Using the retrieved cloud parameters together with satellite geometrical parameters, and prescribed surface albedo and ozone profiles, the cloudy-scene TOA reflectance without aerosol is calculated with a radiative transfer model. A difference between space-based spectrometer measurements of reflectance with the model calculated cloudy-scene TOA reflectance reflects the radiative impacts of smoke above clouds. The advantage of this approach is that it bypasses the assumption of aerosol microphysical properties and retrieval of ACAOD. On the other 
hand, the approach would be subject to large uncertainties when smoke AOD is high and aerosol interference in SWIR cloud retrieval is not negligible. The approach would not be applied to dust because of its spectrally flat AOD. All these methods only provide estimates of aerosol radiative effect at TOA, which is not adequate for assessing aerosol climate impacts. For example, atmospheric heating rate induced by above-cloud aerosols is essential to the understanding of aerosol impacts on the development of underlying clouds (Johnson et al., 2004; Wilcox, 2010).

In summary, recent developments in both active and passive remote sensing provide an unprecedented opportunity for quantifying aerosol above clouds and advancing the understanding of aerosol climate forcing. Future efforts are needed to further explore these capabilities and improve the accuracy of ACAOD and DRF. Although the lack of reliable measurements makes it challenging to conduct rigorous validations of satellite retrievals of ACAOD and DRF, inter-comparing different methods should be carefully performed, keeping in mind the strengths and limitations of individual methods. In addition to providing observational constraints for aerosol DRF and impacts on cloud development, satellite observations of ACAOD can be used to improve the estimate of aerosol intercontinental transport (Yu et al., 2008, 20I2b), because the intercontinental transport often occurs above the low-level clouds.

Acknowledgements: We acknowledge the NASA support via the Science of Terra and Aqua program (NNXAH66G for HY and NNX for ZZ), both managed by R. Eckman. We thank Hyoun-Myoung Cho for helping in producing the image and Yuekui Yang for helpful discussion.

\section{References}

Abel, S. J., H. J. Highwood, J. M. Haywood, and M. A. Stringer, The direct radiative effect of biomass burning aerosols over southern Africa. Atmos. Chem. Phys., 5, 1999-2018, 2005.

Chand, D., T. Anderson, R. Wood, R. J. Charlson, Y. Hu, Z. Liu, and M. Vaughan, Quantifying above-cloud aerosol using spaceborne lidar for improved understanding of cloudy-sky direct climate forcing, J. Geophys. Res., II3, DI3206, doi: 10.1029/2007JD009433, 2008.

Chand, D., R. Wood, T. L. Anderson, S. K. Satheesh, and R. J. Charlson, Satellite-derived direct radiative effect of aerosols dependent on cloud cover. Nature Geosci., 2, I8I184, doi:10.1038/ngeo437, 2009.

Coddington, O. M., P. Pilewskie, J. Redemann, S. Platnick, P. B. Russell, K. S. Schmidt, W. J. Gore, J. Livingston, G. Wind, and T. Vukicevic, Examining the impact of overlying aerosols on the retrieval of cloud optical properties from passive remote sensing, J. Geophys. Res., I I5, DI02II, doi:I0.1029/2009JD012829, 2010.

de Graaf, M., P. Stammes, and E. A. A. Aben, Analysis of reflectance spectra of UVabsorbing aerosol scenes measured by SCIAMACHY, J. Geophys. Res., I I 2, D02206, doi: 10.1029/2006JD007249, 2007. 
de Graaf, M., L.. G. Tilstra, P. Wang, and P. Stammes, Retrieval of the aerosol direct radiative effect over clouds from spaceborne spectrometry, J. Geophys. Res., II7, D07207, doi:I0.1029/20IIJD017160, 2012.

Dubovik, O., Holben, B. N., Eck, T. F., Smirnov, A., Kaufman, Y. J, King, M. D., Tanre, D., Slutsker, I., Variability of absorption and optical properties of key aerosol types observed in worldwide locations, J. Atmos. Sci., 59, 590-608, 2002.

Forster, P., V. Ramaswamy, P. Artaxo, T. Berntsen, R. Betts, D.W. Fahey, J. Haywood, J. Lean, D.C. Lowe, G. Myhre, J. Nganga, R. Prinn, G. Raga, M. Schulz and R. Van Dorland, 2007: Changes in Atmospheric Constituents and in Radiative Forcing. In: Climate Change 2007: The Physical Science Basis. Contribution of Working Group I to the Fourth Assessment Report of the Intergovernmental Panel on Climate Change [Solomon, S., D. Qin, M. Manning, Z. Chen, M. Marquis, K.B. Averyt, M.Tignor and H.L. Miller (eds.)]. Cambridge University Press, Cambridge, United Kingdom and New York, NY, USA.

Haywood, J. M., S. R. Osborne, and S. J. Abel, The effect of overlying absorbing aerosol layers on remote sensing retrievals of cloud effective radius and cloud optical depth. Q. J. R. Meteorol. Soc., 130, 779- 800, 2004.

Herman, J., P. Bhartia, O. Torres, C. Hsu, C. Seftor, and E. Celarier, Global distribution of UV-absorbing aerosols from Nimbus-7/TOMS data, J. Geophys. Res., 102, I69II16922, 1997.

Hsu, N. C., J. R. Herman, and S.-C. Tsay, Radiative impacts from biomass burning in the presence of clouds during boreal spring in southeast Asia. Geophys. Res. Lett., 30, I224, doi:I0.1029/2002GL0I6485, 2003.

Hu, Y, M. A. Vaughan, Z. Liu, K. Powell, and S. Rodier, Retrieving Optical Depths and Lidar Ratios for Transparent Layers Above Opaque Water Clouds From CALIPSO Lidar Measurements”, IEEE Geosci. Remote Sens. Lett., 4, 523-526, 2007.

Jethva, H., O. Torres, L. A. Remer, P. K. Bhartia, A color ratio method for simultaneous retrieval of aerosol and cloud optical thickness of above cloud absorbing aerosols from passive sensors: Applications to MODIS measurements. IEEE Trans. Geosci. Rem. Sens. 2012 (submitted)

Johnson, B. T., K. P. Shine, and P. M. Forster, The semi-direct aerosol effect: Impact of absorbing aerosols on marine stratocumulus. Q. J. R. Meteorol. Soc., I30, I407-I422, 2004.

Keil, A., and J. M. Haywood, Solar radiative forcing by biomass burning aerosol particles during SAFARI 2000: A case study based on measured aerosol and cloud properties, J. Geophys. Res., 108, 8467, doi:10.1029/2002JD002315, 2003.

Knobelspiesse, K., $\quad$ Cairns, B., $\quad$ Redemann, J., Bergstrom, R. W., and Stohl, A.: Simultaneous retrieval of aerosol and cloud properties during the MILAGRO field campaign, Atmos. Chem. Phys., I I, 6245-6263, doi:I0.5 I 94/acp-I I-6245-20 I I, 20 I I.

Meyer, K., S. E. Platnick, L. Oraiopoulos, and D. M. Li, Estimating the direct radiative forcing of absorbing aerosols overlying marine boundary layer clouds in the southeast Atlantic using MODIS and CALIOP, 2012 (in preparation)

Peters, K., J. Quaas, and N. Bellouin, Effects of absorbing aerosols in cloudy skies: a satellite study over the Atlantic Ocean, Atmos. Chem. Phys., II, I393-I404, doi:I0.5 I94/acp-II-I393-20II, 20II.

Russell, P. B., R. W. Bergstrom, Y. Shinozuka, A. D. Clarke, P. F. DeCarlo, J.L. Jimenez, J. M. Livingston, J. Redemann, O. Dubovik, and A. Strawa, Absorption 
Angstrom Exponent in AERONET and related data as an indicator of aerosol composition, Atmos. Chem. Phys., I0, II 55-I I69, doi:I0.5194/acp-I0-II 55-2010, 2010.

Schulz, M., et al., Radiative forcing by aerosols as derived from the AeroCom presentday and pre-industrial simulations. Atmos. Chem. Phys., 6, 5225-5246, 2006.

Stephens, G. L., D. G. Vane, R. J. Boain, G.G . Mace, K. Sassen, Z. Wang, A. J. Illingworth, The CloudSat mission and the A-Train: A new dimension o space-based observation of clouds and precipitation. Bull. Am. Meteorol. Soc., 83, I77I-I 790, 2002.

Torres, O., et al., Aerosols and surface UV products from Ozone Monitoring Instrument observations: An overview, J. Geophys. Res., I/2, D24S47, doi: I0.1029/2007JD008809, 2007.

Torres, O., H. Jethva, and P. K. Bhartia, Retrieval of aerosol optical depth over clouds from OMI observations: Sensitivity analysis and case studies. J. Atmos. Sci., 69, 1037I053, doi:I0.1I75/JAS-D-II-0I30.1, 2012.

Waquet, F., J. Riedi, C. Labonnote, P. Goloub, B. Cairns, J.-L. Deuze, and D. Tanre, Aerosol remote sensing over clouds using A-Train observations. J. Atmos. Sci., 66, 2468-2480, 2009.

Waquet, F., C. Cornet, J.-L. Deuze', O. Dubovik, F. Ducos, P. Goloub, M. Herman, T. Lapionak, L. Labonnote, J. Riedi, D. Tanre', F. Thieuleux, and C. Vanbauce, Retrieval of aerosol microphysical and optical properties above liquid clouds from POLDER/PARASOL polarization measurements. Atmos. Meas. Tech. Discuss., 5, 60836145,2012

Wilcox, E. M., Stratocumulus cloud thickening beneath layers of absorbing smoke aerosol. Atmos. Chem. Phys., 10, II769-II777, 2010.

Winker, D. M., M. A. Vaughan, A. Omar, Y. Hu, K. A. Powell, Z. Liu, W.H. Hunt, and S. A. Young, Overview of the CALIPSO mission and CALIOP data processing

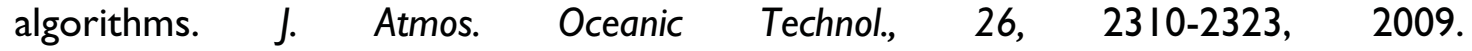
doi:I0.I I75/2009JTECHAI28I.I.

Winker, D. M., et al., The CALIPSO mission: A global 3D view of aerosols and clouds. Bull. Amer. Met. Soc., 91, I21 I-1229, 2010.

Yu, H., Y. J. Kaufman, M. Chin, G. Feingold, L. Remer, T. Anderson, Y. Balkanski, N. Bellouin, O. Boucher, S. Christopher, P. DeCola, R. Kahn, D. Koch, N. Loeb, M. S. Reddy, M. Schulz, T. Takemura, and M. Zhou: A review of measurement-based assessments of aerosol direct radiative effect and forcing. Atmos. Chem. Phys., 6, 6I3666, 2006.

Yu, H., L. A. Remer, M. Chin, H. Bian, R. G. Kleidman, T. Diehl, A satellite-based assessment of transpacific transport of pollution aerosol, J. Geophys. Res., I/3, DI4SI2, doi:I0.1029/2007JD009349, 2008.

Yu, H., Y. Zhang, M. Chin, Z. Liu, A. Omar, L. A. Remer, Y. Yang, T. Yuan, and J. Zhang, An integrated analysis of aerosol above clouds from A-Train multi-sensor measurements, Remote Sens. Environ., I 2I, I25-I3I, 2012a.

Yu, H., L. A. Remer, M. Chin, H. Bian, Q. Tan, T. Yuan and Y. Zhang, Aerosols from overseas rival domestic emissions over North America, Science, 337, 566-569, 20I2b. 
(a) $2007 \mathrm{DJF}$

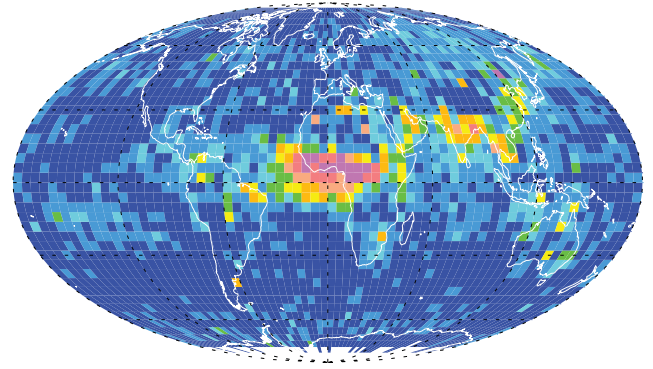

(c) $2007 \mathrm{JJA}$
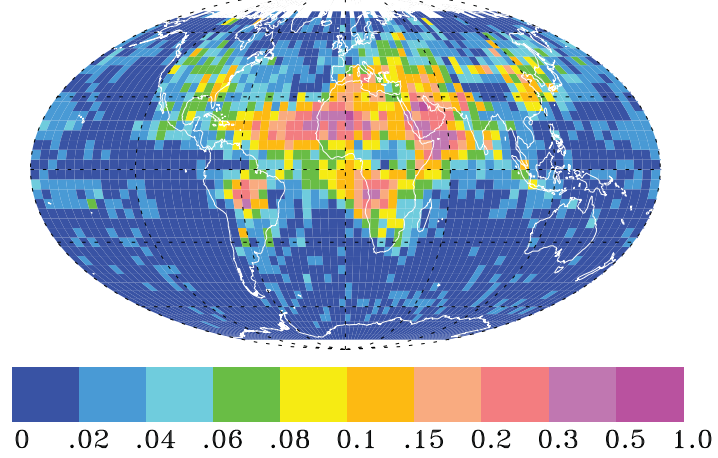

(b) 2007 MAM

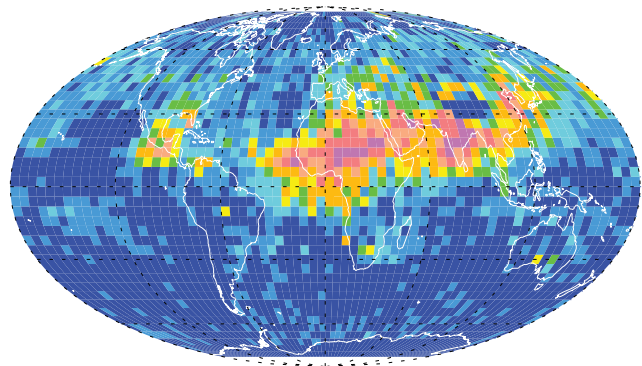

(d) $2007 \mathrm{SON}$
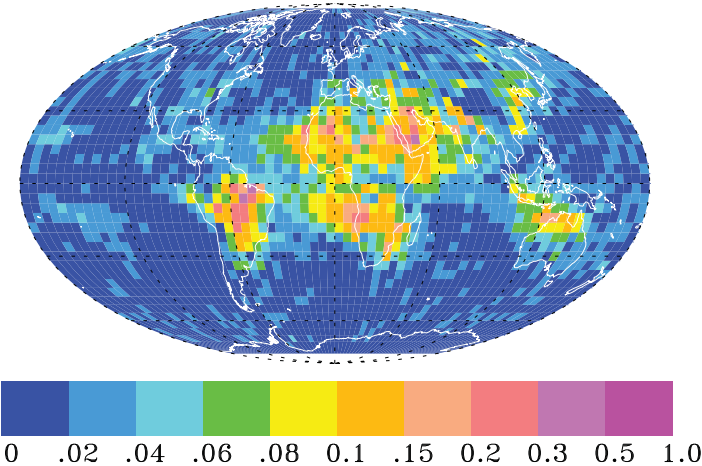

Figure I: CALIOP seasonal mean AOD (at $532 \mathrm{~nm}$ ) above low-level clouds (cloud top less than $4 \mathrm{~km}$ ) for 2007. CALIOP $5-\mathrm{km}$ aerosol and cloud layer products are aggregated into $5^{\circ} \times 4^{\circ}$ grids during a season. AOD is set to 0 when CALIOP doesn't detect aerosol layers above clouds. 
a) CALIOP Attenuated Backscatter
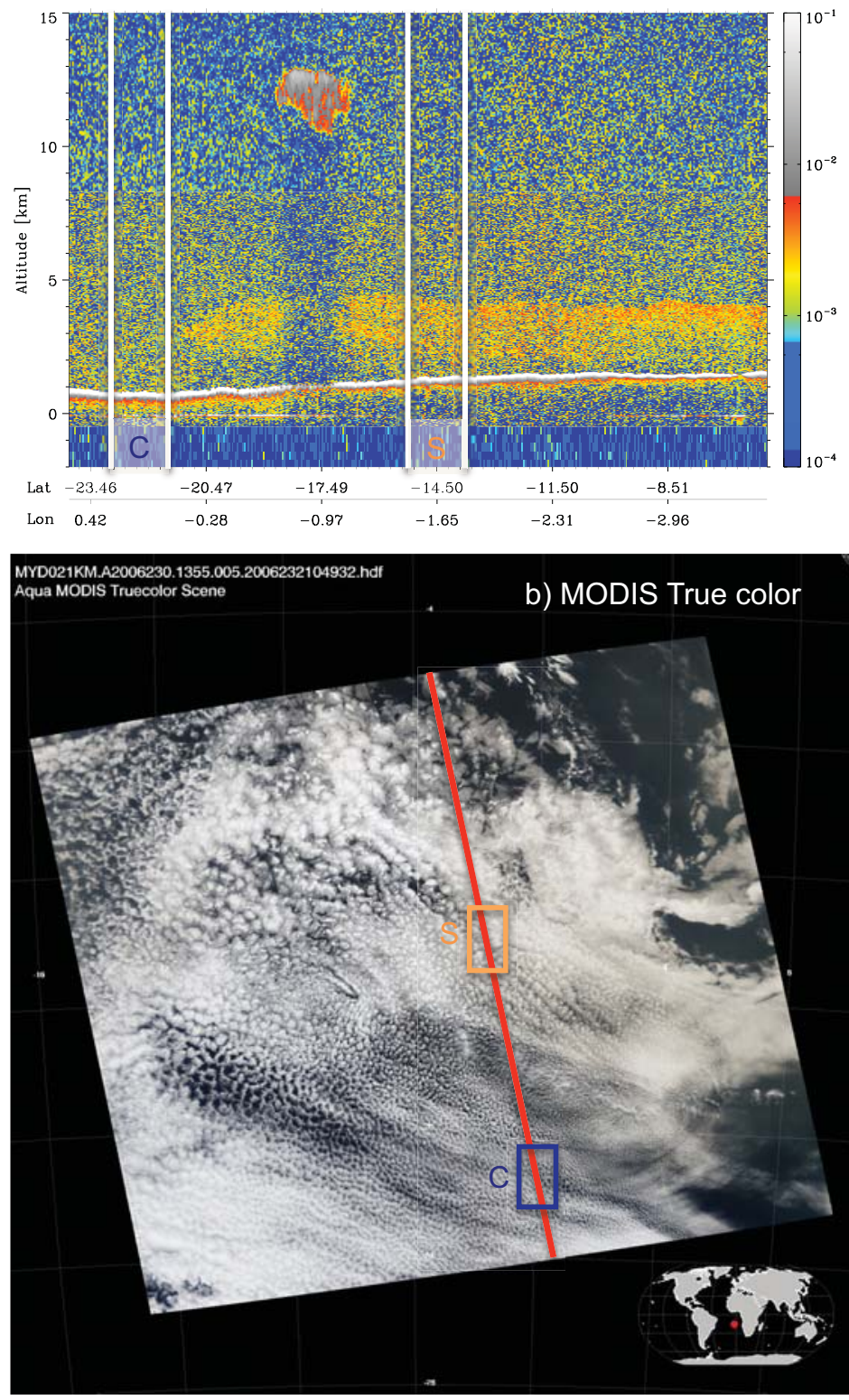
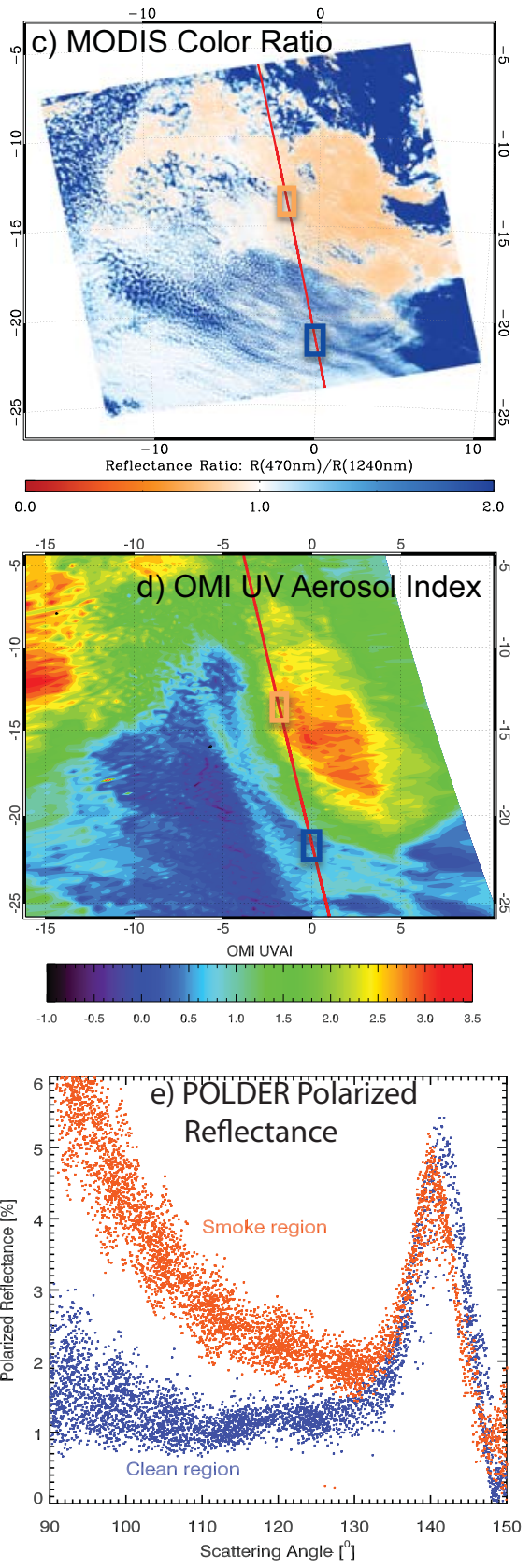

Figure 2: A-Train observations of smoke aerosol above clouds over Atlantic Ocean off the coast of southwestern Africa on August 18, 2006: (a) CALIOP attenuated backscatter $\left(\mathrm{km}^{-1} \mathrm{sr}^{-1}\right)$ profile, showing extensive aerosol layer above clouds north of $17^{\circ} \mathrm{S}$ and relatively clean air south of $21^{\circ} \mathrm{S}$ (a representative smoky region - box $\mathrm{S}$ and clean region - box $C$ are marked for reference); (b) MODIS true color image with the CALIOP track overlaid; (c) MODIS color ratio for the reflectance at 470 and $1240 \mathrm{~nm}$; (d) OMI UV aerosol index; and (e) POLDER polarized reflectance at 865 as a function of scattering angle in the clean (blue dots) and smoky (red dots) regions. 